\title{
Imaginary Penalty and Identity Conflict: The Dilemma and Strategies of Multiple identities in Substance Abusers in Chinese Drug Policy
}

Apei Song ( $\sim$ songasa.711@gmail.com )

Xiamen University

Zhongyuan Ren

Xiamen University

\section{Research Article}

Keywords: Imaginary Penalty, Identity Dilemma, Substance Abusers, Drug Policy, Self-management Strate-gies

Posted Date: December 14th, 2021

DOl: https://doi.org/10.21203/rs.3.rs-1154659/v1

License: (c) (i) This work is licensed under a Creative Commons Attribution 4.0 International License.

Read Full License 


\section{Abstract}

Background: Exploring why the national drug policy failed is an important issue. Although the theory of "Imaginary Penalty" points out the relationship between ideology and policy-making, it ignores the systemic nature of drug control and the voice of drug addicts.

Methods: This study takes substance abusers who live in urban communities as the research participants. Using qualitative research data, this study explores how individual drug abuse experiences are identified and classified by structural forces and how individuals manage their daily life.

Results: The study finds that law enforcement agencies (Narcotics Control Office (NCO), Police Station , and Community Assistance Group (CAG)) have different attitudes toward Substance abusers and generate different managements, forming multiple governance models, and then shaping the multiple and incomplete Substance abusers' identity dilemma. Drug addicts perceive the dilemma, and they adopt the strategies of spatial isolation (hidden flow), disconnection from experience (temporal isolation), and instrumental cooperation to continuously re-adjust and achieve identity recovery from the bottom up with the "possible citizens" narrative logic.

Conclusion/importance: Through evaluating the effectiveness of self-management strategies, this research integrates the Chinese drug rehabilitation situation, expands the specific performance of "Imaginary Penalty" in the law enforcement system, and presents the limitations and positive value of self-management strategies.

\section{Introduction}

The International Drug Policy Coalition (IDPC) declared war on drugs as defeated in $2018^{[1]}$ (Lancaster et al., 2013). At the same time, the situation of China's anti-drug work was also very severe ${ }^{[2]}$. In this context, a lot of studies have been devoted to exploring the causes of the bankruptcy of the drug eradication movement, but most of them consider the aspects of drug policy, anti-drug laws, and drug capital (Brook,2010; Seear\&Fraser,2014). It is a top-down approach to curb the drug problem. For example, some studies have focused on implementing illegal drug policies and civil resistance (Hughes et al., 2017; McConnell, 2015; O'Malley, 2012; Scherlen, 2012). Hughes (2017) concluded that research on drug laws and policies has always focused on significant changes, current conditions, and situational analysis but failing to consider historical and procedural considerations. Emergency is manifested because many studies discuss the contradiction between policy-making goals and actual policies (Fraser \& Moore, 2011; Lancaster \& Ritter, 2014; Moore \& Fraser, 2006; Seear \& Fraser, 2014). The purpose is to supplement drug policy research and adjust drugs established policy goals for related harms and crimes (Moore \& Fraser, 2006; O'Malley, 2012; Seear \& Fraser, 2014; Margaret Pereira, etc., 2020).

In current academic practice, researchers seldom describe substance abusers' lifestyles from their perspective. Some scholars are concerned about the physical health and recovery of drug addicts(Frank \& David,2017; Fraser \& Valentine,2018; Kiran, 2017). They have not studied the facts of drug addicts' 
management and actions in political practice. Thus, scholars less explore how the individualized experience of drug use is identified, classified, and dealt with by structural forces, and ignore Substance abusers how to avoid stigmatizing life, and what strategies they use possibly under the pressure of policies, systems, and social relations. Therefore, I pay attention to the individual's understanding of the identity of addicts, the experience of life difficulties, and internal differentiation in Chinese anti-drug practice. Then, I explore the entanglement and tension between drug use experience, self-management, and political models with a law enforcement analysis framework.

In the following, at the theoretical part, I use and develop the theory of "Imaginary Penalty," synthesizing the practice of drug treatment in China, then expanding its specific performance and explaining its heterogeneity and richness from the perspective of "law in the action." In empirical research, collecting and using the specific experience of "drug governance" and "self-management" materials, I integrate and present the different management models of law enforcement agencies and the resulting structural identity dilemma. Then I describe the self-management strategies of drug addicts who have perceived the identity dilemma. Thus, the article is presented explicitly as: "Law enforcement management and identity dilemma," "Substance abusers' self-management strategies," and "Effect evaluation: Could selfmanagement strategies break through the dilemma? "

\section{Literature Review}

\subsection{The development of Imaginary Penalty}

The imaginary penalty is derived from the work of the same name by Carlen (2008), based on fiction (fiction is derived from the French psychoanalyst Jacques Lacan). Carlen draws on the concept of fiction to demonstrate various crimes, security politics, and how populist ideology constitutes the appearance of criminal law and practice. Furthermore, it points out that an imaginary penalty is based on a kind of (government, legislature) "imagination" intuition, which is the pursuit of new knowledge by imagination. Imaginary penalty reveals the struggle between creating, understanding, and risk of crime, security, and policy in practice. Therefore, Carlen believes that this intuitive logic would hinder new knowledge of crime and be overcome by a more imaginative, open, and diverse law rule.

In 2020, Pereira researched on an imaginary penalty when studying the failure of Australia's drug policy. A number of scholars pointed out that an imaginary penalty with knowledge of illegal drug use is an essential (for example, an independent and problematic situation) attempt by a sovereign state to establish an effective government (see Maher, 2002; Fraser, 2015; Thomas et al.,2016), they point making politicians prioritize political interests rather than adopting alternative punitive drug control (Carlen, 2008; Hope, 2008). In addition to understanding the influence between policy-making and politicians' games, the concept of imaginary penalty, which likes Pat Carlen's field experience at the Australian prison Optima in 2005 , helps to think about the possibility of criminals' social integration between the dual tensions of specific ideological constraints and social practice's creative openness. Pereira believes that drug policy is an imaginary drug control with limited effectiveness and implementation, manifesting in the tension 
between drug consumption, professional practice, and drug services. The tensions just described contribute to the failure of Australia's drug policy. Given all that, the concept of "Imaginary Penalty" focuses on how ideology affects legislation and policies. Specifically, how to form anti-drug laws based on popular willingness and attitudes of political parties in political party disputes(Pereira, 2020). Therefore, We can define it as: the government based on various ideologies presupposes the formation of drug laws and policies.

However, although Imaginary Penalty emphasizes the role of imagination and ideology in policy formulation, there are still two unclear points that need to be discussed and expanded. One is the insufficient discussion of the specific performance of Imaginary. Carlen and Pereira explore the concept of Imaginary Penalty through empirical research, the former proposes this concept which is relatively general, and the latter only discusses the condition of political party disputes. In addition to the political consciousness that politicians describe and strive for the preference of the public, it also very important to know how the ideology of the nation or mainstream social culture revolves around drug rehabilitation. I think the specific performances of Imaginary varies are not shown, especially outside of party disputes. The cases of drug rehabilitation in China could present more details. Executors (The enforcers included the police, CAG and NCO), participating in drug rehabilitation management, show certain consciousness and tendencies, including awareness of national security, social citizenship education, and public risk. By analyzing drug treatment cases in China, we can present more systematic and specific imaginary features and specific experiences in drug treatment management, high politics and the interaction with the public.

Second, Pereira's research follows a very classic policy research path and highlights the gap between policy formulation ("law in the book") and implementation ("law in action"). The current discussion of the Imaginary Penalty is still at the stage of policy formulation. It does not pay attention to the inheritance and development of its imaginary at all levels in the policy implementation process. There is an overall execution system for drug rehabilitation. Besides the group of people who make decisions at the high political level, many executors are also participating in the governance. Their consciousness intensifies the imaginary operation and creates the procedure and mode for them to turn ideal things into reality through political practice. Actions at the executive process show how imaginary features and ideologies are substantiated and deepened into reality. Therefore, the imaginary investigation at the law in action can echo the previous point, presenting the imaginary penalty's concrete and accurate production and practice process.

\subsection{Research on drug abusers}

There are mainly two types of issues on drug users: how to achieve rehabilitation and how to reduce harm. The former focuses on the recovery of physical health, to interpret the physical and emotional changes of drug addicts through the mechanism of drug abuse and addiction (Heather, 1998; Yi et al., 2018; Shi et al., 2019; Wang et al., 2019; Zeng et al., 2019; Zhong et al., 2019; Linda, 2014). The latter has a broader scope of discussion, following with rehabilitation treatment, basic injuries of physical health, 
and discussing justice and recovery in social relations, political situation, and rights of drug addicts (Melamede, 2005; Milloy et al., 2008; Shirley-Beavan et al., 2020). Therefore, studies on harm reduction must pay attention to the influence of authority, family structure, and social structure on drug addicts. It presents a top-down analysis context and relies on a politicized approach.

Using strategies to reduce harm is filled with the imagination of the governing subjects. In the process of practicing these ideologies, some help the rehabilitation of drug addicts, and some invisibly aggravate their harm. For example, Camilla (2018) discovered that Australians who inject drugs are subject to frequent social discrimination, leading to health deterioration and unhealthy well-being. Alana and Honoria (2016) analyzed that young people living in the former Soviet Union who lived in New York City were stigmatized by their communities and families, hindering their access to drug treatment and harm reduction services and gradually depriving Substance abusers of their self-esteem. Lynda (2019) believes that understanding the drug problem requires value neutrality. The government and service departments should be responsible for their remarks to guide the implementation of treatment as soon as possible.

The ideology of harm reduction guides the research and practice of social identity rehabilitation of drug addicts to assist them in achieving physical rehabilitation and reconstructing substance users' identity in society. These studies on reconstructing the rehabilitation social identity of drug addicts are mainly structured (Pereira et al.,2020; Moore et al.,2017; Turner,1973; Longabaugh et al., 2010), using structural power to assist drug addicts in achieving rehabilitation. Structural power presupposes the type and situation of drug addicts and sets up what they should look like after successful rehabilitation. It is hoped that addicts will no longer be shackled by addiction in the future. However, this process is politicized with structural forces.

Some problems cannot be realized in transforming the value of harm reduction from ideology to practical operation. Analyzing this gap, at first we need to pay attention to how the rehabilitation process of substance abusers works in specific situations and the real problems are different from the original intention of reducing harm. Second, it is necessary to examine the understanding and actions of drug addicts carefully, take the actions of drug addicts to deal with governance and difficulties, and reflect on the limitations of political imagination in governance.

\section{Method And Analysis Framework}

\subsection{Field situation}

The research was conducted from November 2019 to July 2020, getting cooperation with Social Organization Q, police station, NCO, and three communities. I used in-depth interviews and literature research (policy documents) method to collect and analyze materials.

Social Organization Q relies on the project "Provide Intervention Support Services for Registered Drug Addicts and Their Families in the Jurisdiction", setting up the L Workstation to manage three communities. There are about 90 registered Substance abusers in the $L$ Workstation. Among them, male 
drug addicts are 66 , around $73 \%$, female drug addicts are 24 . L Workstation also provides the exclusive personal file, including decisions of community drug rehabilitation, detoxification procedure, detailed information of drug addicts, recording community rehabilitation/drug detoxification agreement, urine test records, methadone treatment records, monthly interview records, and past judicial decisions. Social Organization $Q$ also introduced the local police station, community assistance group, and the communities to me, knowing the process of drug rehabilitation and the targets of finishing detoxification. I also took the initiative to contact the director of the NCO of City $\mathrm{X}$ to obtain a relatively macro-level strategic knowledge and work philosophy for drug rehabilitation.

\subsection{Procedure}

The materials of the literature research include drug rehabilitation files and legal policy documents. $\mathrm{L}$ workstation provides detailed documents for drug addicts. I also collected and analyzed some related policies and legal documents from official websites, including the Drug Law (2008) and the Drug Rehabilitation Regulations (2011).

The in-depth interview was divided into two stages: interviews with drug addicts and with the NCO, police station, and CAG. Social Organization Q assisted the interview's contact and communication, and finally, 14 substance abusers and 10 staff of the NCO, police station, and CAG were interviewed.

Interviews with drug addicts focused on the following aspects: perception and response to stigma, understanding, and narrative of drug use, health significance, national drug control agents, strategies, and actions integrated into life. Then talking with the NCO and CAG in four aspects: management methods and requirements, how to carry out the agency's tasks, how to distinguish and judge drug addicts' rehab status, how to interact with drug addicts in the agency. After finishing the preliminary interviews, we focused on the follow-up interviews with 10participants, whose narratives constitute the core points of this article. The specific situation is shown in Table 1:

Table 1. In-depth Interviewee. 


\begin{tabular}{|c|c|c|c|c|c|c|c|}
\hline NO. & Nickname & Age & gender & $\begin{array}{l}\text { Education } \\
\text { (years }^{[3]} \text { ) }\end{array}$ & Role & $\begin{array}{l}\text { Drug abuse } \\
\text { History } \\
\text { (years) }\end{array}$ & Work or not \\
\hline A & Feng & 50 & Male & 6 & Drug user & 10 & No \\
\hline B & Xin & 60 & Male & 6 & Drug user & 20 & No \\
\hline C & Song & 43 & Male & 16 & Drug user & 5 & $\begin{array}{l}\text { Staff in the } \\
\text { market }\end{array}$ \\
\hline D & Ping & 33 & Female & 8 & Drug user & 21 & No \\
\hline E & Min & 41 & Male & 9 & Drug user & 12 & delivery man \\
\hline$F$ & Wen & 31 & Female & 6 & Drug user & 12 & No \\
\hline G & Zhong & 48 & Female & 9 & Drug user & 15 & No \\
\hline $\mathrm{H}$ & Huang & 26 & Female & 16 & $\begin{array}{l}\text { Staff of } \\
\text { CAG }\end{array}$ & None & Social worke \\
\hline I & Lee & 35 & Male & 16 & $\begin{array}{l}\text { Leader of } \\
\text { NCO }\end{array}$ & None & Capitan \\
\hline $\mathrm{J}$ & $\mathrm{PH}$ & 37 & Male & 13 & policeman & None & policeman \\
\hline
\end{tabular}

Among the nine participants in the follow-up interview in Table 1, the top 7 are substance abusers, among which Ping (D), Wen (F), and Zhong (G) are women. Song(C) has the highest education among all substance abusers who graduated from the university. The others generally graduated from junior high school or elementary school. Respondents have a history of taking drugs for 5-22 years, and their drug consumption mainly includes heroin and synthetic opioids (methamphetamine). These participants were detained at least once in a detention center or a Compulsory Drug Institution (CDI) for drug-related crimes. $\mathrm{Xin}(\mathrm{B})$ is currently in a relapse lawsuit, but it is challenging to be sentenced to a CDI for physical disease. The seven Substance abusers are all in the community rehabilitation stage. The CAG needs to pass urine tests and interviews regularly to monitor whether they are eligible for relapse or stable life. The eighth participant is the social worker responsible for communication in the CAG. He has worked in the project team for one year and six months and is familiar with various tasks and each registered drug user's personality and attitude. The ninth participant is the director of the NCO. He is very clear about the diverse work of drug control. During the interview, he cited drug policies proficiently and described the operation of grassroots public security organs (police stations), community assistance, education, and social organizations. $\mathrm{PH}$ is a local policeman, mainly in charge of drug rehabilitation and anti-drug work in the community. He is a front-line policeman who has been engaged in drug tasks for many years. In the end, we recorded and sorted 200,000 words of interview materials and a total of 50,000 words in various archive materials, regulations, and publicity manuals. 
However, since the article is composed of 10 participants with different identities and experiences, it inevitably focuses more on understanding the management style and behavioral possibilities of drug addicts, unable to provide general conclusions and grasp the overall drug governance features.

\subsection{Ethical considerations}

The research is supported by the department of Sociology at X University and Q Social Work Service Organization. Before starting the interview, I explained to the participants that no private information would be involved. The materials obtained are only used for research, and all participants are anonymously protected during the investigation. Each participant has rights to refuse answering sensitive questions, and the researcher could not force the expression. They also can withdraw from the interview at any time, and they can say No.

\subsection{Framework: bilateral law enforcement}

The analysis framework of bilateral law enforcement aims to expand the imaginary penalty from the formulation to the management execution and hope to enrich the discussion of the continuity of the imaginary penalty in practice(see figure 1). And this framework is wary that in addition to the gap between groups (legislation and law enforcement), there is also a gap between law enforcement agencies and law enforcement targets within law enforcement. The feature of this framework is considering the interaction with law enforcement objects. In other words, using an interactive perspective, It explores the dynamic process of mutual penetration of legal forces and individual forces. Subjects included in the framework all belong to the drug treatment system, and as executors, they can transform ideology into practice.

The bilateral law enforcement process focuses on law enforcement practices and the action strategies of law enforcement targets and considers Substance abusers' law enforcement situations. We can discuss the effects of "Imaginary Penalty" in the law enforcement process, the kind of difficulties that have been produced in practice, and how the object of law enforcement (substance abusers) strives to break through the pressure brought by law enforcement with this framework. In the end, it theorizes the interaction between law enforcement practice and law enforcement objects and evaluates the possibility of breaking through imaginary penalties from the bottom-up.

\section{Management Of Law Enforcement And Identity Dilemma}

Feng et al. (2004) believed that it is imperative to pay attention to the diversity of substance abusers' identities in the process of drug control. A series of anti-drug campaigns in China ${ }^{[4]}$ made drug addicts not only consumers but also victims and lawbreakers(Bao, 2017). These multiple political identities have continued nowadays.

4.1. Drug laws and policies: Quasi-citizenship 
Drug rehabilitation policies and laws emphasize the drug rehabilitation model, behavior change measures, and drug addicts' management system, relying on the "People's Republic of China Anti-drug Law (2008)" (referred to as the Drug Law) and "Drug Rehabilitation Regulations (2011)" (referred to as the Regulations).

At first The Drug Law basically specifies the aims, that is, to prevent and punish drug-related crimes, to maintain social order, and to enact this law. Next, the Drug Law stipulates that anti-drug is a social responsibility, it contains prevention and governance, and emphasizes the diversity of subjects, including but not limited to state agencies, social groups, enterprises, institutions, and other organizations and citizens. The drug policy practice mechanism is responsible for government leaders and relevant departments, and society participates widely. In social moral cultural value oriented projects, the government/ the law explicitly encourages encouraging social donations to anti-drug work, report drug violations and crimes (provide commendations), and encouraging volunteers to participate in anti-drug publicity and education and social services for drug rehabilitation. The purpose of the law is to popularize drug prevention knowledge, enhance citizens' awareness of drug control, and improve citizens' ability to resist drugs consciously. Also, it is speculative, which is mainly reflected in the distinction between drug control and different drug use behaviors:

Drug control is an independent chapter. Control the cultivation of the original medicinal plants of narcotic drugs-prohibit illegal attention, extraction and processing, smuggling, etc. Narcotic drug extraction and processing plants, storage warehouses-national key alert targets. Implement control of narcotic drugs and psychotropic drugs, implementation of a permit and inspection system (Lee-interviewee I, 2020)

Although the Drug Law states 'simultaneous prohibit planting, production, sales, and use, ${ }^{[5]}$ it mainly focuses on combating drugs' manufacture and trafficking. The critical warning items are illegal smuggling and trafficking by groups. For drug abusers, the Drug Law further distinguishes drug treatment departments, treatment procedures, and arrangements in drug treatment measures (basically similar to the "Drug Rehabilitation Regulations").

Unlike the Drug Law's comprehensive scope, the Regulations indicates enforcement guidance for drug rehabilitation. The general provisions declare that the "Regulations on Drug Rehabilitation" aim to standardize drug rehabilitation, help drug addicts quit, and maintain social order. Also, drug rehabilitation's operation requires three participants: the government, the drug committee, and social forces. The government is responsible for cooperating with public security organs, health administration, and drug supervision and management departments to carry out drug abuse monitoring, investigation, and publicizing the results. The civil affairs, social security, education, and other departments provide guidance and support for rehabilitation and vocational skills training for community drug rehabilitation and rehabilitation by their duties. Therefore, the implementation subject was further refined into the township government (Chinese called Street Office) responsible for community drug rehabilitation and detoxification (later, a community assistance group was established). 
The Drug Law and the Regulations act as a set of re-screening mechanisms to Screen socially qualified Substance abusers. Among them, Substance abusers who have experience in trafficking, manufacturing, and using are the first to elimination by drug policy. But some of them who only use the drug have the opportunity to become citizens again if they voluntarily participate in drug rehabilitation or passively compulsory drug rehabilitation. Of course, the former is also easier to obtain policy assistance.

Go to drug treatment institutions to receive treatment on your own, and the public security organs will not impose penalties on their original drug abuse... No discrimination in school enrollment, employment, social security... Personal information is kept confidential, and those who will not relapse within three years will no longer be implemented dynamic management and control, commendation for outstanding drug rehabilitation ("Drug Rehabilitation Regulations" $p$ 6-7)

We have accepted a teenager who voluntarily rehabilitated drugs. His father brought him to the police. There is no precedent. The policeman at this police station was very insightful. He asked the teenager to be supervised and managed, and the community drug rehabilitation observed his treatment performance. They will not link drug use to the website and register him for the time being, but he will be connected to the Internet if he relapses or does not change. This is a kind of preferential treatment not linked to the national personal files. It is much more convenient for him to do many things (Huang-interviewee $\mathrm{H}$, 2020).

Rules in the regulation, such as 'will not impose penalties,' which means that even if the drug takes a large dose and the form is terrible, those who participate in voluntary drug rehabilitation can be exempted from responsibility and will not be sent to a Compulsory Drug Institution (CDI). Interviewee Huang's experience confirms this point.

The Drug Law and the Regulations emphasize and promise the rights of becoming a legal citizen. The specific manifestations are: First, after the detoxification period, Substance abusers can enjoy citizenship in education, work, and social welfare benefits. Then, after the rehabilitation period (no relapse), the CAG promise to end surveillance and dynamical control. Through these two points, drug users are expected to become legal citizens again. Thus, we can regard substance abusers within the period of detoxification and rehabilitation as "quasi-citizens" who are subject to inspection and discipline. However, it is precisely because of the nature of the investigation and screening that the quasi-citizenship of drug addicts has become a traditional way of discrimination in education, work, and social welfare within the two-year detoxification period and the three-year rehabilitation period.

Also, it is reasonable that quasi-citizenship points to the process of becoming a legal citizen again. But in fact, comparing the "Criminal Law of the People's Republic of China (2015)", "the Marriage Law of the People's Republic of China (2001)", "the Social Insurance Law of the People's Republic of China (2010)", "the Law of the People's Republic of China on the Protection of Minors (2012)", and even some regulations such as "Regulations on Application and Use of Motor Vehicle Driver's License (2012)", we discover that individuals with drug abuse experience are difficult to maintain the treatment of ordinary citizens in terms of education, work, and social welfare and they are excluded from the ownership of 
children and the use of motor vehicle driver's licenses. That is to say, the Regulations and other people's livelihood penalties involving drug addicts or substance abusers are treated differently.

4.2. Law-enforcement agencies: the patient, the deviant, or risk-taker?

In implementing drug rehabilitation policies and laws, the leading agencies are the Narcotics Control Office (NCO), Police Station, and the Community Assistance Group (CAG).

The NCO is altogether called the Office of the Narcotics Control Committee established by governments at all levels. From the central government to the local government, the National NCO's management and execution system can find every level. Police Stations are subordinate to the public security organs and important tentacles of the $\mathrm{NCO}$ at the grassroots level. Police stations, as well as police and correctional officers, directly connect with Substance abusers. They are responsible for carrying out various specific drug control and rehabilitation work at the micro-level. They also need to complete political targets for specific urban drug control work. CAG's members are composed of police officers from the police station, community staff, social workers from social organizations, almost maintained 4 or 5 workers. A CAG is responsible for tracking 7-8 people and is accountable for the grassroots government-subdistrict office. The local NCO administers more than a dozen subdistrict offices and participates in management remotely. During the interview process, the state agency's macro and micro level departments present three different identity recognition: Patients, Deviant, or Risk-taker.

In interviews with the NCO head, Lee repeatedly emphasized that the Narcotics Office treats drug addicts as patients:

Combating drug production, drug trafficking crimes and controlling drug substances, and drug addicts "two attacks and two controls" unique political practices, focusing on drug addicts, improving drug addicts' risk assessment and hierarchical and classified control measures, and treating disabled drug addicts in rehabilitation tackling tough battles and strictly controlling drug addicts... it is the task of our Office of Narcotics Control. In fact, at the level of understanding drug addicts, we think addicts are patients, patients with physical diseases, and behavioral dependent diseases that need to be recovered(Lee-interviewee I,2020)

NCO's focus is to detect relapse behaviors and conduct health-risk assessments for drug addicts. Their work philosophy is expressed as Surveillance, classification, and arrangement of Substance abusers and their friends, especially to control drug addicts, not to participate in drug trafficking or other illegal activities.

Our country classifies drugs into three categories: traditional drugs are opioids, synthetic drugs, and new drugs. The current rules and policies are still standard traditional and synthetic drugs, mainly heroin and methamphetamine. This type of drug is difficult to quit, and those with a long history of drug use are infected with this type of drug. Maybe it's useless to enter the camp several times because the behavior dependence is too strong. It is a painful and laborious process for them to participate in rehabilitation 
and addiction withdrawal. The new type of drugs is different. It acts on nerve excitement, and if you overeat, it will be damaged. However, we also communicated with the psychology experts that this kind of drug dependence is not healthy, so we usually detain them for 15 days before putting them back. Those who have received administrative detention will not affect the issuance of a certificate of no criminal record. (Lee-interviewee I, 2020)

I was caught smoking heroin on H East Road (June 2019). My body is so terrible, and I have a lung obstruction. Still, because of serious illness (a chronic obstructive pulmonary disease with acute onset, lung infection), Xiamen Compulsory Drug Institution (CDI) did not accept me, and I am still rehabilitating in the community (Xin-interviewee B, 2019).

Lee believed that traditional Substance abusers and new Substance abusers (totally a political division) are very different. Their degree of pathology is different, and the evaluation of Medicalization expertise is also discrepant. Traditional Substance abusers are physically dependent and difficult to control themselves. As long as they are not involved in criminal acts such as drug trafficking, the CAG and Compulsory Drug Institution (CDI) will help them quit the addiction. This process is also a consideration of physical health. However, it is interesting that CDI did not dare to contain Xin, who has a very high frequency of relapse and a history of heroin use for nearly 20 years. Because Xin recently suffered from a relatively severe disease (obstructive pulmonary disease), government agencies did not welcome him. They do not want substance abusers to stay in institutions with risk of death, so in the end, the police asked Xin to continue drug rehabilitation in the community and called "it is a patients' right." The arbitrary nature of law enforcement is particularly prominent in this case.

In contrast, if they are not excessive use, new-Substance abusers will, at most, do some administrative detention. These people are mentally relaxed, and when they wake up, they do not have too much material dependence and could recovery by themselves.

In an interview with a member of CAG, Huang mentioned Xin and the leader of local NCO Lee's verbal expression, Huang could not understand:

For the sake of safety, aren't Substance abusers just offenders? They have broken the law. I can admit that they are not criminals, but only drug trafficking can lead to drug trafficking, and drug trafficking can promote more drug abuse. They are essential consumers in the drug trafficking chain. It can be said that they are not criminals for not participating in drug trafficking, but they are also breaking the law. And if my neighbor is a drug addict, I will avoid him unconsciously. I don't know when he will suddenly hurt the people around him. Discrimination is not necessarily accurate, but rejection will occur. It is my selfprotection!! (Huang-interviewee H, 2019).

Huang presented the real thoughts of some members of the CAG. Although their work helps drug addicts achieve social integration in drug rehabilitation, they are also very alert to the potential destructive power of drug addicts to order and other citizens' safety. Their surveillance, to a certain extent, the job must be 
able to predict and evaluate whether a sure addict will generate potential damage into action. So CAG members treat drug addicts as deviants, those who need supervision and help.

"We have to protect the safety of the residents in our jurisdiction. Safety is always the first and professional task. We are worried that Substance abusers will gather crowds to relapse and sell drugs in private. It is all illegal. The raids are also for their good, especially the constant those who have relapsed (those) cannot be controlled by themselves. We also gave them an occasional vigilance. We will think more about them before relapse" (Police Officer PH-interviewee J, 2019).

The police station and the policeman treat drug addicts as potential risk-takers of public order. They believe that the life trajectory of substance abusers is also an uncertain factor that affects the safety of living spaces. When the public and private balances and interests are in harmony, the grassroots workers in police stations and compulsory drug rehabilitation centers all expressed an attitude of "no tolerance." Putting Substance abusers within a strict enforcement framework is the safest strategy.

\subsection{Summary: Multiple governance and identity dilemma}

NCO is relatively mediocre, which is mainly responsible for drug control and crime-fighting. It tends to treat drug addicts as prospective citizens and its main work philosophy is to guide all citizens to participate in drug rehabilitation and improve the transformation mechanism for prospective citizens. On the one hand, it promotes and educates drug knowledge and guides ordinary citizens to realize the harm of drugs, consciously manage physical health; on the other hand, in drug rehabilitation, NCO urges drug addicts to get rid of addiction through risk ratings.

The main jurisdiction of the Police Station is to control and prevent drug addicts' relapse and risky behaviors through urinalysis, hair testing, and unannounced visits. The main work concept is to maintain "society safe," which means controlling Substance abusers in the jurisdiction to avoid the spread of drugs and other illegal activities. Therefore, drug addicts are regarded as potential risk-takers of public security.

CAG needs to conduct micro-day-to-day interactions, and they integrate assistance, education, and supervision. Although the CAG also collect some needs from drug addicts and provide corresponding services, such as docking vocational training, temporary work resource links, etc. The task of notifying the urine test once a month obscures the special nature of the help, support, and education of the CAG team. Instead, it also emphasizes that CAG members are alert to the risky behaviors of drug addicts. Drug addicts are regarded as a group that needs daily supervision at this level, not the object of being helped and taught.

As a result, the imaginary of different executive bodies (NCO, police station, CAG) have formed multiple governance practices in drug rehabilitation management. And the multiple governance in drug rehabilitation have created the identity dilemma of the substance abusers in action--multiple and incomplete identities. Multiplicity is manifested that the national drug policy and law, and management departments have given substance abusers multiple and contradictory identities. This split identity 
makes it impossible for abusers to rely entirely on laws and policies to implement their obligations and rights and difficulty maintaining identity recognition in each system stage. Among them, the differences within the agency department need to be more cautious. It can be expected that the identification of patients or offenders/deviants cannot inherit and implement quasi-citizens' screening function, nor can it subtly change the definition of criminals stigmatizing substance abusers by the public (table 2).

Table 2. multiple governance and identity dilemma.

\begin{tabular}{|llll|}
\hline law enforcement & Specific content & Identity & Dilemma \\
\hline $\begin{array}{l}\text { Drug law and } \\
\text { policy }\end{array}$ & $\begin{array}{l}\text { the Drug Law and the } \\
\text { Regulations. }\end{array}$ & $\begin{array}{l}\text { Quasi- } \\
\text { citizen }\end{array}$ & $\begin{array}{l}\text { multiple and incomplete } \\
\text { identities }\end{array}$ \\
\hline National Agency & $\begin{array}{l}\text { Narcotics Control Office (NCO) } \\
\text { Police Station } \\
\text { Community Assistance Group } \\
\text { (CAG) }\end{array}$ & $\begin{array}{l}\text { Patients } \\
\end{array}$ & Deviants \\
\hline
\end{tabular}

Incompleteness is manifested in two aspects: One is the limited acceptance by the general public of the civic status of drug addicts. Drugs are closely connected with national security in modern Chinese history. The danger of drugs has been continuously strengthened and shaped in the story of modern colonial history. In the author's investigation, drug addicts cannot be called "patients" or "victims," nor even lawbreakers in the general sense, but "criminals" signals. This frequently appearing label does not come from the law, but it flashes in the community life and cultural life. The "drug use history" has become a sharp edge in the separation of personal social relations.

Second, incompleteness is also manifested in limited acceptance in professional employment. During the period of drug rehabilitation, drug addicts are mainly engaged in some part-time jobs. During these three years, the local grassroots public security departments are not giving a non-criminal certificate, so drug addicts take on higher occupations risk when facing work change or economy pressure.

Multiple agencies produce identity dilemmas. This unexpected consequence prevents drug users from not only being unable to maintain the same identity recognition at different stages of the drug rehabilitation system but also unable to rely on anti-drug laws and policies to reintegrate into society and become ordinary people in the sense of daily life. So, how do substance abusers recognize their identity dilemma? How do they understand and deal with dilemma to live comfortably?

\section{Substance Abusers' Self-management Strategies}

\subsection{Perception of identity discrimination in Substance abusers}

When shifting from the perspective of structural analysis to the discussion of actors, the most important thing is to understand the cognitive differences between the role of the analyst and the addicts 
themselves. As Lan (2011) said, "Under the long-term acceptance of state agency authoritative leadership and governance, I inevitably form an epistemological perspective and interactive mode of observation and understanding." We need to change our position from a speculator to a drug addict perspective.

In the process of discussing the anti-drug social plan and drug rehabilitation management methods from a structural perspective, It explains the identity dilemma that has been produced from the establishment of the government anti-drug project to the continuous development (time dimension, local difference) that is not conducive to the rehabilitation and re-citizenship of drug addicts. However, actors who have been in the grassroots drug rehabilitation stage for a long time do not have historical and expansive perspectives and thinking about the identity discrimination and difficult life they have suffered. When they perceive and understand their situation, they will base it on reality. Specific communication subjects in life, or stress events, make simple judgments and general impressions. What dominates them to form this relatively narrow cognition is often the sudden strengthening of emotions at a certain moment.

Substance abusers' limited perception of their hardship is mainly aimed at a few specific subjects with a high frequency of contact in daily life: police, social workers, community workers, and other citizens. The interpretation of these role management methods in previous article conforms to the image of drug addicts facing drug addicts in their lives. Therefore, from the perspective of the trust relationship, the trust of drug addicts in them is roughly presented as: "NFO > CAG > police station" of course, this kind of trust performance is not a fixed pattern. The occurrence of conflicts and strong emotional expressions will always affect the trust situation. Drug addicts develop a flow of cognition and trust in other subjects, which forms their interpretation of their identity dilemma. However, the discomfort of fragmented and different identities is difficult to coordinate and self-consistent.

\subsection{Self-management strategies}

In order to cope with the police law enforcement, frequent urine examinations, and daily supervision of CAG in daily life, avoid the repeated expression and memory reappearance of drug use experience, and avoid the obstacles and negative effects of drug rehabilitation on life. Combining their limited resources, drug addicts have developed unique identity management strategies from the perspective of social space, time, and resources, to break through the identity dilemma and develop a more "dignified" and "resourced" social life.

\section{A. Spatial isolation: Fleeing from one another in urban communities}

The Drug Law and the Regulations stipulate substance abusers' mobility during detoxification. If they (abusers) leave the city (where they registered), they need to use their ID cards to "register" in the community. Only then will they be allowed to take long-distance transport and book hotels. The digital information network unreservedly show whether substance abusers are in detoxification period.

When I went to Fuzhou to visit relatives, I had to register the type of case, the reform through labor, the handling unit, and my family information. Who is my wife? My phone call number? Although I was issued 
this certificate, the local police station took me for a urine test the first day I stayed in the hotel. (Feng interviewee A, 2019)

Internal-city mobility is often unrestricted. However, compared with the restrictions on outbound movement, there is a risk of personal information exposure. Even in an interview with Huang, she mentioned that she had only recently obtained the contact information of a drug user who had been in the CAG for two years and learning that this abuser had other residences.

Now there are only two people in my family, me and my father, and everyone else goes to seek refuge with my uncle. Because what I did before was so disappointing, my uncle lost trust in me, and now I am not allowed to seek refuge... (community). They call me once a month. I will not force an interview on the phone. Before, I lived with my girlfriend in Nanping city (Min-interviewee E, 2019).

I worked in Zhangzhou city before, and the community didn't care about it... This time I came out of the CDI. I might not go home and live with my aunt. My aunt's son is still willing to take care of me (Songinterviewee C, 2019).

Abusers show two modes of hidden movement in the city: One is the "smuggling" mode. Take Min as a representative, he secretly left the registered address, did not take the initiative to inform the community whereabouts, and more mind the community inquire about his specific situation. Communication targets of CAG only achieving through short telephone contact. Next, The "exile" model, represented by Song, didn't mind the community asking about the current address because it had many mobile places. CAG also cannot know the movement and residential address.

These two modes of concealment and mobility often do not conflict. The "smuggling" mode focuses on the concealment of the outward destination. It is easy to fabricate the help and education group's requirements if it is a short trip. The "exile" mode emphasizes the concealment of real daily life places to avoid sudden police random urine tests or door-to-door visits with members of the CAG. They(CAG and the Police) have caused damage to personal and neighbor relationships because they'll be exposed to their neighbors as drug addicts. The neighbors would get very tired of them. And these two modes can be flexibly switched at any time depending on the action content of the CAG.

The two models above reflect a common approach to identity conflict: the concealment of stigmatized or marginalized identities is achieved through hidden flows in space. They are also separated from the accessible surveillance space of CAG and police to a certain extent. Space isolation makes the identity defined by CAG and police for abusers stuck in the community, and completely unfamiliar social relationships and impressions in the new space can be reshaped and presented. To a certain extent, this is a very radical way of handling identity. The radical manifests are in a sudden change in space or a specific intended change in stigmatized identities and re-operate. It is also a processing method that requires great courage. 
It is necessary to abandon the original living space's resources and relationships. It is also essential to carefully maintain the new space's identity from being exposed by digital and information networks. When Min lived in his uncle's house to start a new life, his uncle was disgusted with him because of improper management, repeated relapses, and theft. Re-operating the legal identity image is the goal of spatial isolation. Once it fails, it can only be re-operated in another area.

B. Broke: abandon the past and look forward to relieving

In addition to managing identity conflicts in a spatially isolated manner, the participants also presented a way of mitigating identity conflicts at the temporal level, striving to separate themselves from past drug abuse behaviors, shaping a new self.

Now I have no other plans. When the community rehabilitation is over, I will take another driver's license test, run a taxi, or be a Didi (private taxi company) driver... I live with my parents, and their pensions can support me partially. Don't worry about finding a job. Drug use ruined me. I used to be a bank clerk. It is impossible to go back to my life in the future, but if I want to start again, I can't get drugs (Songinterviewee $C, 2020$ ).

I don't want the police to come to my house suddenly to take urine samples. I have tried very hard to control and manage myself to remind myself of my past drug abuse and cherish the current life of family reunions. Still, every urine test reminds me of my past drug abuse behaviors. I can't do it without community rehabilitation. Let yourself start again (Wen-interviewee $F, 2019$ ).

Respondents in the narrative who showed a strong tendency to separate from past drug use behaviors are looking forward to the coming of relieving CAG and finishing drug rehabilitation. They imagine that without these dynamic controls, they will seal the past bad behavior from the time dimension and start a new life. Both Song and Wen hope that drug abuse is just an experience, which means abuse experience has little influence on their everyday life and relationships with their girlfriends and children.

Every contact of the CAG invisibly reminds them of various connections with past drug abuse experiences. The sudden urine test forced Wen to recall her past drug use experience. The more anxious is that Song does not know if he is in love or is preparing for other important life links when he next surprises his urine test. Thus the explanation does not end, and isolation from the past self is an imagination that is difficult to realize fully. The current break with past behavior is only an exploratory effort.

There is no way...I also thought about driving Didi and taxis before. If you have experience in drug use, you will find out they don't provide chance for you. Except for part-time jobs in society, which one is better? Will not open the door for Substance abusers (Feng-interviewee A, 2019)

Feng presented his own experience. Isolation is only a temporary conservative strategy, social integration is not as simple as imagined. The public's understanding of the identity of Substance abusers will still lead to job discrimination. 
Separation from past behavior is a virtual action, but it is unrealistic for individuals to want to ignore actions they have done in the past. Past life experience has been internalized in the individual's cognition and behavior habits. Isolating the past, looking forward to the future, and preserving the present can only be an individual's inner choice and attitude and cannot face the unity of the past, present, and future. They have never been able to face the dilemma of social integration and multiple identities, nor can they reconcile with the past self. Of course, this cognitive strategy of separating the past has relieved the pressure of identity dilemmas to a certain extent and provided the addicts with the motivation and inner strength to continue to persist.

C. Instrumental cooperation: use identity to obtain resources

Compared with the previous two strategies, the separation and concealment of stigma in space and time, Instrumental cooperation has limited the spread of identity conflicts and focused on using the cognition of identity in different agents to achieve and realize beneficial interests through formal collaboration. Specifically, it can be manifested in three cases: receiving various subsidies, issuing a non-crime certificate, and cooperating with the police station to exchange urine tests for resources, like Min and Ping:

2008/5/22 sensitive glaucoma treatment application assistance; 2009/4/21 want to participate in methadone treatment; 2009/6/15 asked if I can help apply for the cost of methadone replacement treatment; 2009/10/14 take methadone invoice to apply for subsidies; 2009 /11/16 Take the methadone invoice to apply for subsidies; 2015/7/13 Min wants to apply for subsistence allowance again; 2018/7/25 Min hopes to apply for affordable housing; 2019/4/26 Min currently uses for subsistence allowance as a family household. Submit the approval materials; 2019/5/9 Min's family subsistence allowance is approved; the 2019/12/19 roll to the security room number can get a two-bedroom and oneliving house (Min's personal file).

I had received a community subsidy for breast cancer before, and my brother (Min) also got money to treat glaucoma. The community asked me, the Guangming Fund, to reimburse the cost. Later, we went to the community if we had a problem. They are more reliable. The sewer was a bit blocked last week, and I also asked the city to solve it (Ping-interviewee D, 2020).

Since 2008, Min has realized that drug use experience and offenders' and patients' identities can help him more easily obtain various government and social resources linked to the CAG. The most prominent feature of these resources is that Min is not clear and difficult to access. During the whole process, Min only needs always to show a firm attitude towards drug treatment. Then he will give difficulties and needs a priority. For example, the affordable housing policy is a policy for urban residents with low incomes who cannot afford to buy a house. However, abusers themselves are more likely to be packaged into lowlevel people who urgently need affordable housing. Therefore, Min and Ping applied for the minimum guarantee fund faster, applied for affordable housing in December, and got a two-bedroom and one-living room. 
I remember that Policeman Chen from the police station gave Liu, who had already been expatriated, a non-criminal record and could open it. Liu's son served as a soldier, and his family needs a certification to prove the innocent background. Liu came to the police station to ask Chen, and Chen gave a non-criminal certificate before Liu's son could join the army. Chen regretted it. All ex-posters can open a non-criminal record or certification, but the risks need to be borne by policeman Chen himself, and the pressure is immense (Huang-interviewee $H$, 2019).

In another case, to help his children serve as soldiers, Liu went to the police station and asked for a noncriminal certificate, proving that Liu's family identity is innocent to the government auditors.

A non-criminal certificate is a kind of certification material to show the legalization of citizenship. It also means that abusers should complete community drug rehabilitation, and detoxification will not leave a record in the public security organs, which further proves that the identity of criminals considered by society is misunderstood and distorted. However, the general security organs are unwilling to issue a noncriminal certificate for Substance abusers. After all, abusers are different from ordinary law-abiding citizens. They are still a factor of insecurity in real society. If a non-criminal certificate is issued, the local public security agency must guarantee that the person will not violate law or discipline. However, as far as the general security agency is concerned, it is its fundamental responsibility to ensure local security. Various task indicators do not indicate whether it is feasible to issue a non-criminal certificate. That makes the police themselves bear the later risks of political behavior and rules, which police officers mainly regretted.

Xin, nearly 60 years old, has a severe illness and can only detoxify in the community. During the 2020 epidemic, he lost contact for almost three months. Accounting for Xin's past drug abuse history, the CAG believes that he has relapsed. However, in May, Xin took the initiative to contact the community anti-drug committee to indicate that he was willing to undergo a urine test, showing that he could not be arrested immediately. The community must assist in applying for a retirement pension. What is even more paradoxical is that the community and the police agreed to his request because of bureaucratic management's complexity. If Xin is caught by another police station and filed a case, the paperwork and handover work between them and other agencies will be very tedious and troublesome. To avoid extra work brought by the bureaucracy, the local community and the police station agreed to Xin's terms. At the end of May, the CAG accompanied him for a urine test. When leaving the police station, I observed:

Turning to the alley, Xin was here, still a little rickety, rubbing his hands slightly faster, his face calm. A middle-aged man in white is standing nearby smoking a cigarette. "Xin?! Why are you here?" "...we are... waiting for someone" Xin's voice was calm. "Didn't you go to take a picture?" "I'm from the police station" The middle-aged man in white, throwing away his cigarette butt, immediately stopped our inquiry. "Then let's go first." The anti-drug station workers continued to walk and "leave here first" I couldn't help but feel the urge to run away. When I came to the alley, I turned my head back, and a group of people gathered in front of Xin like a swarm of people (observing at the police station, 2020.5) 
"They have to make up the capture process. If other police stations catch them, they still need to make up various procedures" (Huang-interviewee $H$, 2019)

Xin's interaction with the police station is an exchange logic. He cooperated with the police to complete the arrest in exchange for promises such as urine testing done by the law ${ }^{[6]}$, letting him go home that day, and the community as soon as possible to assist in applying for a pension. Further study reveals that this real-time interactive performance is based on the comprehensive understanding of both parties' identities for drug use. Xin continued to talk about the dilemma of his identity as a patient and a lawbreaker, prompting the police station to be unable to enter the camp of severe illnesses. The police station understood that Xin's age and physical condition would not negatively impact his social impact even if he relapsed, so he asked Xin to complete the arrest plan and complete the case filing.

Instrumental cooperation does not mean acceptance or active integration. It is not about accommodating multiple identities into a single positive identity but strategically making full use of the advantages and disadvantages of different identities in interacting with CAG and social citizens to present a more suitable identity. As a result, instrumentality is more directed towards focusing on the assembly of multiple identities to reflect conflict and exerts creativity.

The most prominent commonality of the three strategies for managing identity conflicts is that the management techniques for drug problems have been transferred to individuals who demand the freedom to carry out their lives (Margaret Pereira et al., 2020). Substance abusers need to self-determine and manage identity conflicts and risks. They face comprehensive and complex multiple identities compared to the NCO and CAG. Multiple identities conflict inevitably maintains a certain high relapse rate, and the government's security and crime control goals, therefore, having to pay a higher political price (Garland, 1996).

For this reason, the strategies of concealed mobility of drug addicts (spatial isolation), disconnection from the past (temporal isolation), and instrumental use of identity can help enrich the information at the actor level under the operation of political behavior and show the process and purpose of selfmanagement that individuals reassemble multiple identities and creativity. The drug rehabilitation policy is a goal-oriented ideal product of dominating the culture and able to absorb the improper operation of political behavior from marginal groups' real plight and life, thereby making up for the coexistence of multiple logics of the law and multiple inconsistent governance.

More importantly, these three differentiating strategies are not only simply classified as ideal types. In the process of being narrated and performed recurrently, drug addicts have been repressed and constrained for a long time, constantly and actively re-adjusting and sticking to them together. Depoliticized expression is the characteristic of this process rather than the political characteristics of structural shaping.

\section{Could Self-management Strategies Break Through The Dilemma?}

Page 20/31 
6.1. The dilemma of "imaginary penalty-identity conflict."

The dilemma situation of substance abusers can be called "imaginary penalty-identity conflict." To be more specific, imaginary penalties refer to the government's presupposes' drug laws and policies based on cultural foundations and international drug attitudes. They often display entirely different values and meanings in actual operations and present imaginary characteristics, which means they cannot implement the legislative intent and policy. There is a gap between the intention and the implementation. This differential identity recognition has always affected government departments' political practice, causing Substance abusers to feel a deepening violation of individual rights. Then it makes ordinary people difficultly to accept Substance abusers once they know Substance abusers' identity, even if they have completed the entire legal and policy detoxification process.

So far, the "imaginary penalty-identity conflict" has gradually formed a plight that always affects Substance abusers, emphasizing and demonstrating the incomplete citizenship of abusers. This dilemma is manifested: first, the quasi-citizen plan has failed. In the previous part, we presented the outcome of policies and laws that ultimately shape substance abusers into quasi-citizens. In the Drug Law and the Regulations, it is especially emphasized that abusers who carefully cooperate in drug rehabilitation and complete the task of drug rehabilitation will not be discriminated against in work, education, and social welfare. However, all participants mentioned the problem of job discrimination or difficulty in finding a job.

I can only go to jobs that do not require a long-term contract, so I don't need to show my bank card, social security card, and ID card. If they know that I have experienced drug abuse, I can't make money here. I want to go to the sewer company. They have excellent welfare, two days to relax per week, and five insurances would organize training and travel. (Author: wages?) 3000 a month (Author: You are 3800 a month). But there is stability, security, and welfare, but unfortunately, I can't go. (Zhong-interviewee $G$, 2020).

Zhong presents that "I want to go to the sewer company. They have excellent welfare, two days relax per week, and five insurances would organize training and travel." But he was rejected by the company because of his drug experience. The imaginary penalty design has been implemented by the NCO, police station, and CAG. Still, the promised equality and civil rights have never been fulfilled. It has caused many low-level drug addicts to simply abandon themselves and fall into a stuck loop of "relapse-drug rehabilitation-discrimination-relapse."

The second point is the intensified mistrust relationship between addicts and organizations. To maintain the stability of the area and complete the quarterly task of arresting drug addicts. The police will surprise drug addicts in police uniforms to conduct urine tests on addicts. Substance abusers who fail a urine test are also encouraged to report other abusers in exchange for a lighter punishment. This bureaucratic behavior has completely intensified the contradiction between drug addicts and the police. 
The third point is the arbitrary nature of punishment. The restrictions on drug addicts mentioned in the Drug Law and the Regulations are mainly in long-term monitoring and management. That is, it takes 2-3 years to participate in compulsory rehabilitation or community rehabilitation. Space restriction means crucial detoxification restricts drug addicts in detoxification centers, while community detoxification cannot leave the urban area. Going to other places requires an application; Strictly forbidden to relapse, and those with dire circumstances will be sent to the CDI. Many hidden effects work, such as restrictions and personal information exposure. The characteristic of this kind of hypothetical punishment is to give the grass-roots people a lot of room to operate, and the enforcement is relatively loose. However, the union of operating space reservation and the police's target task of arresting drug addicts produced a political practice in which punitive measures were used arbitrarily. In the narrative mentioned above, the police have an absolute power advantage when dealing with abusers. They can induce and differentiate drug addicts, even to surrender the sanctity of punishment. For example, the policeman can decide whether to continue drug treatment in the community (not sent to a compulsory drug treatment center) or temporarily detain the boy and promise to release him. It has led to drug addicts who, on the one hand, fear the power of the police entirely. On the other hand, they also realize that there are still many possibilities for adjustment even if there is a relapse behavior. For instance, Xin discovered that patients with significant diseases could not be included in CDI.

The problems caused by the misalignment of these three policy assumptions and actual political behaviors have led to a problematic survival situation and multiple incomplete identities and then forced substance abusers to self-manage to alleviate the cramped living space caused by bankruptcy quasicitizen programs, distrustful relationships, and arbitrary punishment.

\subsection{Why can't identity management break through the dilemma?}

To cope with the dilemma of identity conflict, Substance abusers try to use hidden mobility (spatial isolation), complete rupture (time separation), and cooperation strategies to make themselves more like ordinary citizens, hide their personal experience of drug abuse better integrate into society. We can define this process as "A quasi-citizen model developed by individuals." Its primary purpose is to temporarily replace drug policies and legal assumptions that agents have not implemented at all levels. Interestingly, the drug addicts interviewed did not have a real understanding of the relevant laws and policies. Their sense of identity conflict is mainly derived from the police and the CAG's requirements for control, surveillance, and differentiation from ordinary citizens. Although addicts do not understand the various factors of their difficulties, this does not affect the admiration of addicts for non-stigmatized identities and mainstream groups.

Therefore, can these identity management strategies help them break through the predicament and fight for more rights? The answer is no.

From an empirical view, we can feel Chinese substance abusers conduct and manage their identity through an ambiguous relationship with disciplinary regimes. In the spatial isolation strategy, substance abusers place themselves in a new, unfamiliar relationship and conceal the CAG trajectory to reshape 
their new personal identity and prevent the exposure of their drug abuse experience. However, the CAG and the police will immediately believe that Substance abusers have relapsed without repeated inspections and interviews. They will require the drug addicts to participate in a urine test through threats and warnings. Therefore, this disengagement mode is only temporary and highly risky. Broken, the strategy of covering up past experiences in the dust is, even more, a measure of self-deception. If community drug rehabilitation is not completed, CAG's past drug abuse will always be aroused in interviews. Even drug addicts who have completed detoxification and returned to society will be suddenly awakened from memory, which is like a nightmare constantly repeating. Instrumental cooperation is one of the most successful substance addict methods to benefit subsistence allowance, medical insurance, and housing. However, when survival needs are met, drug addicts desire a decent life with dignity. Then, they will lose because of a hopeless lifestyle. For example, they hope welfare jobs, opportunities for reeducation, or good interpersonal relationships, but this often involves the values and ideologies of the entire society on drug use, which is difficult to achieve. If the initial instrumental cooperation obtains resources through a stigmatized identity to survive, the later instrumental collaboration cannot get better resources.

In addition, self-management strategies also exhibit three important characteristics: highly normative, avoiding conflict, and single resources, which leads to limitations in the effectiveness. Highly normative is that drug addicts often express the desire to return to the mainstream culture. That is, in addition to their past drug abuse experience, they are more supportive of the government and the country's big decisions than others. Avoiding conflict is trying to escape or cut into the relationship with the original community, peers, and self, aiming to create a stable and private daily life outside the shadow of legal control. Single resources are that the resources to support the implementation of the strategy come from the life of the drug addicts, lack of sustainability and external resources, and are therefore prone to interruption and duplication.

The three characteristics of self-management indicate that the strategies of drug addicts to cope with identity dilemmas are compliant with mainstream culture, limited to their resources, and have not formed a sub-cultural practice that confronts management power and seeks to fight for their rights from the bottom up. Therefore, the self-management of substance abusers is only a limited self-protective passive action under the disciplinary system.

However, in this section, I used the verb break through instead of break, which is to a certain extent endorsing the bottom-up path development of drug addicts, and it is not in vain. The self-management strategy of drug addicts is an attempt to depoliticize. As the objects of the governance system, they also feel the awareness of national security, social citizenship education, and public risk, but they are different from the subcultural resistance mode. They strive to maintain consistency with the country and society, showing that they are citizens who love their country, the party and society, and hiding their identity and experience of substance abuse from those around them. This unanimity of imagination enables the addicts to gain part of their life autonomy. 


\section{Conclusion}

The life of drug addicts portrayed in this study focuses on the interaction between law enforcement agents and law enforcement objects and conceptualizes it with imaginary punishment, including two parts: organizational governance model and life practice of drug addicts. In implementing drug treatment management, the executive agencies represented by the NCO, the police station, and the community help and education team have formed a diverse governance model with different working concepts. This governance has caused multiple and incomplete identity dilemmas for drug abusers. As a result, drug addicts have been living a surveillance life of stigmatization, high-level control, and identity separation for a long time to alleviate the discomfort of life. Urban drug addicts have adopted strategies such as hidden mobility (spatial isolation), complete rupture (time separation), and instrumental cooperation is adopted to hide personal experiences of drug abuse and try to return to ordinary citizenship. However, in this game of individual identity and political rights, the strategies of Substance abusers have not changed "imaginary penalty-identity conflict."

The contribution of this article is reflected in the following three points. Firstly, I extend the concept of the imaginary penalty based on the legislative and policy-making levels to the management and enforcement stage and present the concrete manifestations of the imaginary in different subjects in the context of drug treatment in China, which forms multiple governance and identity dilemma. When discussing the imaginary in the execution part, I provided a relatively clear interactive analysis framework to explore management practices and describe the specific imaginary design and Operation. It also uses data from the Chinese field to illustrate the possibility and operability of this expansion.

Secondly, In the part of empirical research in the daily life of addicts, it provides findings that are different from similar studies in the United States. Existing research on the identity conflicts of marginalized groups often summarizes the actions of marginalized groups as sub-cultural movements with resistance characteristics. However, Chinese urban drug addicts use self-management strategies to adjust to the social pressure and injustice they feel and actively move closer to the mainstream culture. The marginal groups and the mainstream groups reach a state of symbiosis rather than confrontation under the same norms.

Thirdly, it presents the existing mode of drug control and expresses the voices and demands of drug addicts. I show how the existing drug policy has shaped drug addicts and created multiple identity dilemmas for drug addicts through the agency sector. And once again, starting from the action strategy of drug addicts to manage multiple identity conflicts, the improvement of drug policy must take care of tolerable action strategies at the action level. Therefore, the adjustment of drug policy will point to two crucial dimensions: one is to avoid drug policy in an implementation that creates multiple identities in China; the second is to ensure the strategy of drug addicts to manage identity conflicts and breakthrough identity dilemmas. However, no matter what kind of an adjustment it is, it challenges the "imaginary penalty." The premise of Imaginary drug control is to minimize or eliminate drug-related harm through 
punitive reactions. Although it has eliminated illicit drug use to some extent (Carlen, 2008; Margaret Pereira et al., 2020), it continues to create the conditions and types of identities for drugs to harm society.

It is undeniable that since 2008, the whole axiom system with drug policy as the core has played an important role in supervision, management and crime fighting. After Xi Jinping became president, he emphasized that "drug control is related to national security, national flourish, and people's well-being. If drugs are not eliminated, the fight against drugs cannot be slackened." [6] They formed a horizontal management strategy to combat drug crimes, destroy drug manufacturing and trafficking gang networks, and eradicate drug breeding problems. The government carries out preventive education to develop an atmosphere of consciously resisting drugs in the whole society. It may also be the political basis for the imaginary penalty of drug policies and laws. However, this inevitably means that drug addicts and Substance abusers who return to society will become "others" assembled arbitrarily under the governance strategy. Even if the senior policy executive realizes that it is necessary to look at drug addicts from a new identity perspective, they cannot implement a de-stigmatized identity at all levels of implementation due to the separation of "imaginary and reality." Multiple identities are added to the individual drug addicts, creating more troubles in life. No current axioms are eternally necessary, in axioms' evolution, whenever crises and risks cause certain reactions, we can add axioms or eliminate the existing axioms (Patton, 2000), which means an "imaginary penalty" needs to break through existing knowledge and standpoints. In addition to considering ideology, specific policy implementation and implementation, such as drug addicts' lives and operations of drug rehabilitation systems, which we try to incorporate into drug policy adjustments. And we try to incorporate drug addicts' lives and the operation of drug rehabilitation systems into the content of drug policy adjustment and consideration.

\section{Note}

[1]The International Drug Policy Coalition (IDPC; a global coalition of 170 non-governmental organizations dedicated to drug policy issues) released its latest anti-drug work report in October 2018, calling the global "drug war" a "eye-catching" Failure and led to thousands of murders, public health crises, and human rights violations. The report pointed out that the 10-year global strategy formulated by the United Nations has failed, and the original plan to eradicate all drug markets in 2019 has also failed.

[2] Until 2018, the number of Substance abusers and crime rates in drug rehabilitation and anti-drug programs in China have remained high. Looking at the number of Substance abusers, the current number of registered Substance abusers in China has increased from 70,000 in 1990, at a rate of $15 \%$ to $20 \%$ each year (Liu Jingning, 2012), and reached 2.4 million in 2018. From the perspective of drug relapse and crime rate, in 2018, 504,000 relapsed abusers were seized nationwide, of which 289,000 were abusing synthetic drugs, accounting for $57.3 \%$ of the total; 212,000 abused opioids, accounting for $42.1 \%$, of the whole. As of 2018 , more than 400,000 drug-related cases have been handled in the past ten years, including 140,000 crimes committed by drug addicts. The low penetration and network expansion of Substance abusers mean that China's drug control and rehabilitation programs face severe challenges. 
[4] Since 1729, Emperor Yongzheng issued the first ban on smoking ban (The ban on smoking here refers to opium products). From the beginning, the Qing government insisted on its political stance against drug smuggling. At that time, the elite class with the ability to pay was the main opium consumer group. They believed that “opium (consumption) can alleviate people's sense of loss feeling”(Boliwei,2017:270). During this period, the Qing government's opium control was mainly based on violent suppression. The famous historical event-Lin Zexu's smoking ban occurred at this time. At the beginning of the 20th century, China's rising nationalism once again provoked a controversy about opium consumption. Opium was regarded as a national humiliation and was one of the main reasons for the decline of China's national power at that time. At that time, there were three events across the country. The anti-drug campaigns are: the 10-year anti-drug plan in 1906, the six-year anti-drug plan in 1934-1940, and the new China's anti-drug campaign.

[5]From fourth items of China's Anti-drug Law(2018), Legal address:

https://baike.baidu.com/item/Drug Control Law of the People's Republic of China/10232542?fr=aladdin

[6] This point of view is emphasized in every anti-drug work instruction from 2014 to 2019. For example, the theme in 2014 is "Persevere in carrying out the anti-drug work in-depth," the article in 2015 is "Unswervingly Win the People's War Against Drugs." The theme in 2018 is "Taking the path of governance of the drug problem with Chinese characteristics and resolutely winning the new era." "People's War Against Drugs," "Never Retreat Without a Complete Victory," in 2019.

\section{Declarations}

Author Contributions: Conceptualization, A.S.; methodology, A.S.; software, R.Z.; validation, A.S., and R.Z.; formal analysis, A.S.; investigation, R.Z. and A.S.; resources, A.S.; data curation, A.S.; writing-original draft preparation, A.S.; writing-review and editing, R.Z.; visualization, A.S.. All authors have read and agreed to the published version of the manuscript."

Disclosure statement: The authors reported no potential conflict of interest.

Acknowledgment: I am very grateful to the Qifu Social Work Service Organization for its support in the research, which allowed me to establish a trusting relationship with the participants. Next, thanks also to Prof. Liu Zixi and Prof. Yi Lin for their early amendments, and thanks to Dr. Li Dong, Dr. Huang Yanhua, and Dr. Deng Ran for their assistance in the field development.

Data Availability Statement: The materials that support the findings of this study are openly available in Open Science Framework's online depository, available at https://osf.io/658dv/ Data collected and uploaded by the author of this article 


\section{References}

Administrative Measures for Compulsory detoxification institution by Public Security Organs, implemented on September 28, 2011, reference address:

https://www.itslaw.com/search/lawsAndRegulations/lawAndRegulation?

searchMode=lawsAndRegulations\&lawAndRegulationld=db667a85-1369-41 fa-b0b2-

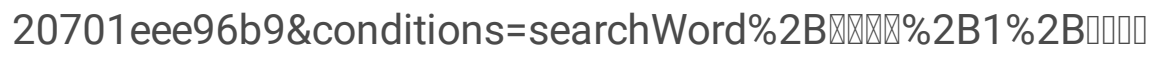

Bao Liwei, translated by Yuan Junsheng, Opium in China: 1750-1950, Beijing: China Pictorial Publishing House, 2017.

Bull, M. (2008). Governing the heroin trade: From treaties to treatment. Ashgate.

Pereira, M., \& Scott, J. (2016). Harm reduction and the ethics of drug use: Contemporary techniques of self-governance. Health Sociology Review, 26, 69-83.

Carlen, P. (2008). Imaginary penalities and risk-crazed governance. In P. Carlen (Ed.), Imaginary penalities (pp. 1-25). Willan Publishing.

China's Drugs White Paper in 2000》

http://www.china.com.cn/zhuanti2005/txt/2005-06/07/content_5883317.htm

Coley, Jonathan. (2018). Gay on God's campus: Mobilizing for LGBT equality at Christian colleges and universities. Chapel Hill: University of North Carolina Press.

Dehlin, Jhon P., Renee V. Galliher, William S. Bradshaw, and Katherine A. Crowell. (2015). Navigating sexual and religious identity conflict: A Mormon perspective. Identity: An International Journal of Theory and Research 15(1):1-22.

Decision on Anti-drug in 1990冈https://zhidao.baidu.com/question/619716734119862452.html

Drug Law of the People's Republic of China (2007/2008), implemented on December 29, 2007, reference address:

https://www.itslaw.com/search/lawsAndRegulations/lawAndRegulation?

searchMode=lawsAndRegulations\&lawAndRegulationld=05c0fc15-7028-47df-81bcaaebd668f13c\&conditions=searchWord\%2BषQ\%2B1\%2B

Drug Rehabilitation Regulations (Order No. 597 of the State Council), implemented on June 22, 2011, reference address:

https://www.itslaw.com/search/lawsAndRegulations/lawAndRegulation?

searchMode=lawsAndRegulations\&lawAndRegulationld=7b102fb1-7fca-4f9b-9820- 
Feng Ke, translated by Xu Youwei. (2008). Crimes, Punishments, and Prisons in Modern China, Jiangsu: Jiangsu People's Publishing House.

Fraser, S., \& Moore, D. (2011b). Governing through problems: The formulation of policy on amphetaminetype stimulants (ATS) in Australia. International Journal of Drug Policy, (22): 498-506.

Fraser, S. (2015). Articulating addiction in alcohol and other drug policy: A multiverse of habits. International Journal of Drug Policy, (31): 6-14.

Garland, D. (1996). The limits of the sovereign state: Strategies of crime control in contemporary society. The British Journal of Criminology, (36): 445-471.

Hope, T. (2008). The first casualty: Evidence and governance in a war against crime. In P. Carlen (Ed.), Imaginary penalties (pp. 43-63). Willan Publishing.

Hughes, C. (2007). Evidence-based policy or policy-based evidence? The role of evidence in the development and implementation of the drug diversion initiative. Drug and Alcohol Review, (26): 363368 .

Hughes, C., Ritter, A., Lancaster, K., \& Hoppe, R. (2017). Understanding policy persistence-The case of police drug detection dog policy in NSW, Australia. International Journal of Drug Policy, (44): 58-68.

Kenneth Surin. (1997). The 'Epochality' of Deleuzean Thought. Theory Culture Society (14): 9-21

Maher, L. (2002). Don't leave us this way: Ethnography and injecting drug use in the age of AIDS. The International Journal of Drug Policy, (13): 311-325.

Lancaster, K., \& Ritter, A. (2014). Examining the construction and representation of drugs as a policy problem in Australia's national drug strategy documents 1985-2010. International Journal of Drug Policy, (25): 81-87.

Lan Peijia.(2019).Struggling to raise children: Globalization, Parental Anxieties and Unequal Childhood. Chunshan Publishing Company

Lee, N., \& Ritter, A. (2016). Australia's recreational drug policies aren't working, so what are the options for reform? The Conversation.

https://theconversation.com/australias-recreational-drug-policiesarent-working-so-what-are-the-optionsfor-reform-55493

Liu Jingning. (2012). Current Status and Trends of Drug Crimes in my country, China Public Security · Academic Edition, (1): 95-99 
Margaret Pereira, John Scott, and Amanda Beem. (2020). Imaginary Drug Control and the. Failures of Contemporary Australian Drug Policy. Contemporary Drug Problems, 47(1): 29-42

McConnell, A. (2015). What is policy failure? A primer to help navigate the maze. Public Policy and Administration, (30): 221-242.

Moore, D., \& Fraser, S. (2006). Putting at risk what we know: Reflecting on the drug-using subject in harm reduction and its political implications. Social Science \& Medicine, (12): 3035-3047

Moon, Dawne and Theresa W. Tobin. (2018). Sunsets and solidarity: Overcoming sacramental shame in conservative Christian churches to forge a queer vision of love and justice. Hypatia 33(3):451-68.

Ning, R. \& Palmer, D. A. (2020). The Resurrection of Lei Feng: Rebuilding the Chinese Party-State's Infrastructure of Volunteer Mobilization. In ruling by Other Means: State-Mobilized Social Movements. edited by Elizabeth Perry, Gzegorz Eckiert and Xiaojun Yan. Cambridge University Press. pp314-344. DOI:10.1017/9781108784146.013

Orit Avishai. (2020). Religious Queer People Beyond Identity Conflict: Lessons from Orthodox LGBT Jews in Israel. Journal for the Scientific Study of Religion (0):1-19

O'Malley, P. (2012). Globalising risk? Distinguishing styles of 'neoliberal' criminal justice in Australia and the USA. In T. Newburn \& R. Sparks (Eds.), Criminal justice and political cultures (pp. 42-60). Willan Publishing.

Paul Patton. (2000). Deleuze and the Political. New York, Routledge.

Pitt, Richard N. (2010). "Still looking for my Jonathan": Gay Black men's management of religious and sexual identity conflicts. Journal of Homosexuality 57(1):39-53.

Palmer, M., Wodak, A., Douglas, B., \& Stephens, L. (Eds.). (2015). Can Australia respond to drugs more effectively and safety: Roundtable report of law enforcement and other practitioners, researchers and advocates. Australia 21. http://australia21.org.au/wp-content/uploads/2017/02/Can-Australia-respondto-drugsmore-effectively-and-safely-Roundtable-report.pdf

Radojcic, Natasha. (2016). Building a dignified identity: An ethnographic case study of LGBT Catholics. Journal of Homosexuality 63(10):1297-1313.

Rodriguez Eric M., Ouellette Suzanne C. (2000). Gay and Lesbian Christians: Homosexual and Religious Identity Integration in the Members and Participants of a Gay-Positive Church. Journal for the Scientific Study of Religion (3):333-347

Scherlen, R. (2012). The never-ending drug war: Obstacles to drug war policy termination. PS: Political Science \& Politics, (45): 67-73. 
Seear, K., \& Fraser, S. (2014). The addict as victim: Producing the 'problem' of addiction in Australia victims of crime compensation laws. International Journal of Drug Policy, 25, 826-835.

Thomas, N., Bull, M., Dioso-Villa, R., \& Smith, C. (2016). Governing drug use through partnerships:

Towards a genealogy of government/non-government relations in drug policy. International Journal of Drug Policy, 28, 34-42.

The 1950 Ban for opium: http://m.law-lib.com/law/law_view.asp?id=15587

The "Compulsory Drug Abuse Law" established in 1995:

http://blog.sina.com.cn/s/blog_4c9fda54010008n9.html

Vines, M. (2014). God and the gay Christian: The biblical case in support of same-sex relationships. New York: Convergent Books.

Wedow, Robbee, Landon Schnabel, Lindsey K.D. Wedow, and Mary Ellen Konieczny. (2017). I'm gay and I'm Catholic: Negotiating two complex identities at a Catholic university. Sociology of Religion 78(1):289317.

Woodell, Brandi, Emily Kazyak, and D'Lane Compton. (2015). Reconciling LGB and Christian identities in the rural South. Social Sciences 4(3):859-78.

Zhou Yongming. Translated by Shi Lin. (2016). China's Anti-drug History in the 20th Century: Nationalism, History and State Construction. Beijing: Commercial Press.

\section{Figures}

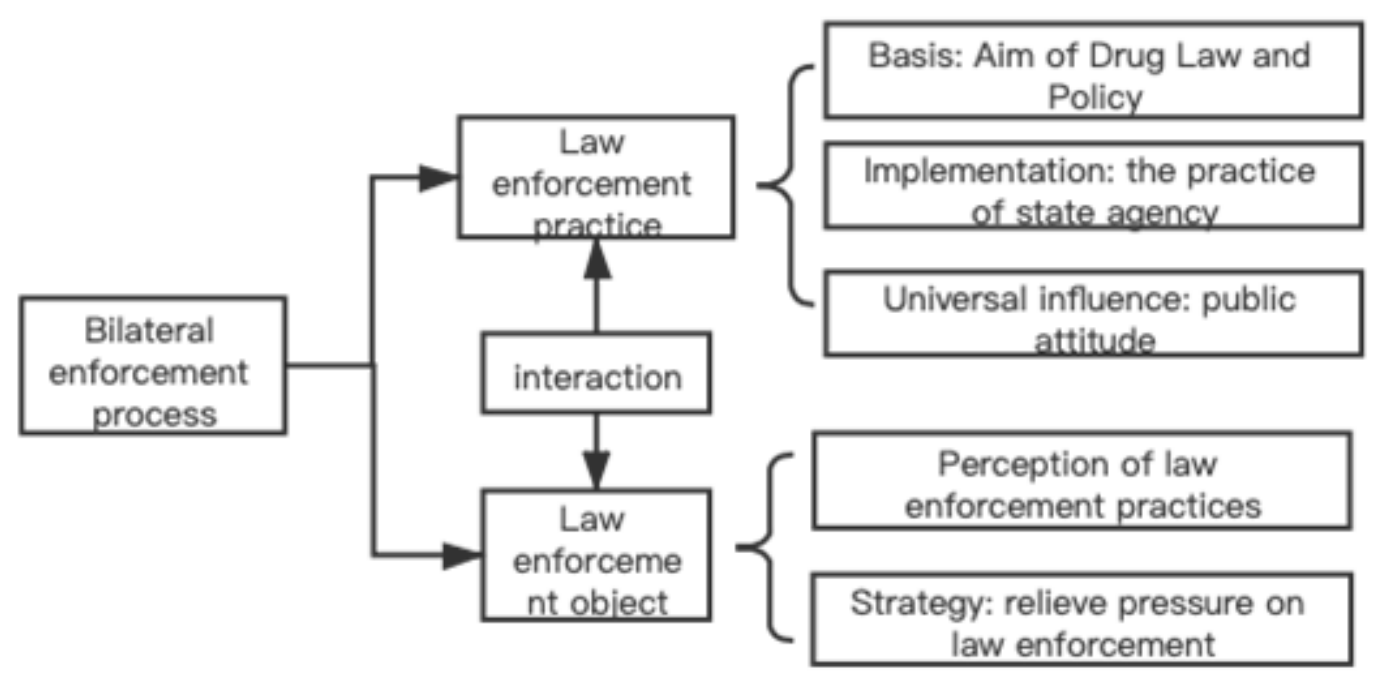


Figure 1

Analysis framework.(PLACE in this section) 